\title{
ESTIMATION OF CHL-A CONCENTRATION IN LAGUNA LAKE USING SENTINEL-3 OLCI IMAGES
}

\author{
Ariel C. Blanco ${ }^{1,2 *}$, Amihan Manuel², Rey Jalbuena ${ }^{2}$, Kristina Ticman², Jommer M. Medina ${ }^{1}$, Edgardo Gubatanga ${ }^{2}$, Ace Santos $^{2}$, \\ Raymund Sta. Ana ${ }^{2}$, Eugene Herrera ${ }^{3}$, Kazuo Nadaoka ${ }^{4}$
${ }^{1}$ Training Center for Applied Geodesy and Photogrammetry, University of the Philippines, Diliman, Quezon City 1101, Philippines ${ }^{2}$ Department of Geodetic Engineering, University of the Philippines, Diliman, Quezon City 1101, Philippines
${ }^{3}$ Institute of Civil Engineering, University of the Philippines, Diliman, Quezon City 1101, Philippines
${ }^{4}$ Tokyo Institute of Technology, Tokyo, Japan
*acblanco@up.edu.ph

KEY WORDS: regression analysis, inland water, water quality, remote sensing, phytoplankton

\begin{abstract}
:
The use of Sentinel-3 Ocean and Land Color Instrument (OLCI) images in estimating chlorophyll-a (total and class-differentiated)a concentration is promising owing to Sentinel-3's 21 bands. This was investigated for the case of Laguna de Bay (or Laguna Lake), Philippines. Field surveys were conducted on 13-17 November 2018 using FluoroProbe, a submersible fluorimeter capable of quantifying concentrations of spectral classes of microalgae. These were regressed with reflectance data obtained from 10-day composite Sentinel-3 reflectance images as well as ten empirical algorithms (indices) for OLCI. Compared to band reflectance, the 10 indices yielded stronger correlations, especially with R665/R709, R674/R709, and (1/R665-1/R709)xR754 with the following respective correlation values: $-0.623,-0.646$, and 0.628 . Multiple regression results indicates that $48 \%$ of the variability of total chl-a concentration is explained by five explanatory (reflectance) variables (R412, R443, R560, R681, and R754) with RMSE of $2.814 \mathrm{ug} / \mathrm{l}$. In contrast, the two indices R674/R754 and (1/R665-1/R709)xR754 accounted for about 46\% of the variability of total chl-a concentration with RMSE of $2.475 \mathrm{ug} / \mathrm{l}$. For diatoms and bluegreen microalgae, R560/R665 and (1/R665-1/R709)xR754 constitute the models with $\mathrm{R}^{2}$ of 0.21 and 0.435 , and RMSE of 2.516 and $2.163 \mathrm{ug} / \mathrm{l}$, respectively. Green microalgal concentration is jointly described by three indices: R560/R665, R674/R754, and R709-R754, with $\mathrm{R}^{2}=0.182$ and RMSE $=1.219$ ug/l. From cryptophytes, the model comprising of R560/R665, (1/R665-1/R709)xR754, and R709-R754 produced an $\mathrm{R}^{2}=0.289$ and RMSE $=0.767 \mathrm{ug} / \mathrm{l}$. It can be said that the empirical algorithms can be used for Sentinel-3 OLCI data providing acceptable estimations of total and spectral classdifferentiated chl-a concentration.
\end{abstract}

\section{INTRODUCTION}

Chlorophyll-a is one of the standard water quality parameters monitored in bodies of water. Typically, chl-a concentration is measured by water sampling and laboratory analysis and/or through in situ measurement using water quality checker/instrument at designated sampling stations. There are however time-consuming, labor-intensive, and costly (Schaeffer et al, 2013). With limited number of sampling stations, it would be difficult to describe the temporal and spatial variability of large scale lake phenomena (Dörnhöfer and Oppelt, 2016). Due to uneven distribution of sampling points and differences in time of sampling/field measurement, these may result in unreliable water quality assessment (Bresciani et al., 2011).

Many studies have utilized remote sensing to assess water quality, describing its spatial and temporal variability. Chlorophyll-a, turbidity, suspended particulate matter, and colored dissolved organic matter (CDOM) are the parameters commonly mapped and monitored using satellite images, particularly those freely available including Landsat images (Chen and Feng, 2016, Manzo et al,. 2015, Palmer et al., 2015). Recent studies have focused on the use of Sentinel-2 and Sentinel-3 data (Toming et al., 2017, Blix et al., 2018, Petus et al., 2019). Toming et al. (2017) retrieved water reflectance, inherent optical properties (IOPs), and water quality parameters including chl-a, total suspended matter (TSM) and CDOM in the Baltic Sea using standard Case-2 Regional/Coast Colour (C2RCC) processing chain. Blix et al. (2018) used and evaluated
Sentinel-3 OLCI L2 products, namely, chl-a, CDOM, and total suspended matter (TSM) to monitor an optically highly complex shallow Lake Balaton. These and other studies estimated total chl-a and not the chl-a associated with different classes of microalgae. The estimation of the latter is important as abundance and proportions/percentages of microalgal classes signify or indicate occurrence of particular environmental phenomena and issues.

Laguna de Bay is a multi-use productive lake in the Philippines devoted to aquaculture, water supply, and transportation of people and goods. The lake supplies significant percentage of milkfish and tilapia sold in Metro Manila and provinces surrounding the lake. Laguna Lake is already being tapped for domestic water supply with water concessionaires abstracting hundreds of million liters per day. The lake is eutrophic and turns green in color when microalgae blooms occur as a result of high nutrient inputs from surrounding watersheds and abundant sunlight. Excessive algae may result in fish kills and affect water supply from Laguna Lake. Abundance of algae in terms of chlorophyll (green pigment) must be mapped and monitored.

This study investigates the applicability and performance of regression models generated from Sentinel-3 OLCI reflectance data and indices in estimating chl-a concentration. The abundance of phytoplankton is estimated not only through total chl-a but also the spectral class-differentiated chl-a concentration. 


\section{MATERIALS AND METHODS}

\subsection{Study Area}

Laguna de Bay (more commonly called Laguna Lake) is the largest inland waterbody in the Philippines with a surface area of approximately 900 sq. km. (Laguna Lake Development Authority, 2017). The lake is shallow with an average depth of 2.5 m only (Santos-Borja and Nepomuceno, 2003). Primary uses of the lake include aquaculture, navigation, and water source for domestic use, irrigation, and power generation.

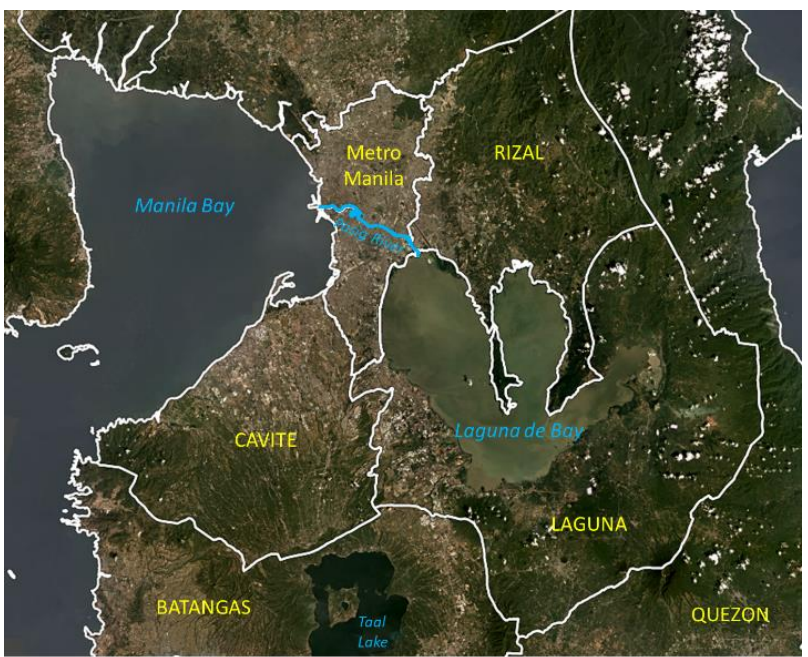

Figure 1. Laguna de Bay ( Laguna Lake) and surrounding land areas. The lake is connected to Manila Bay via the Pasig River

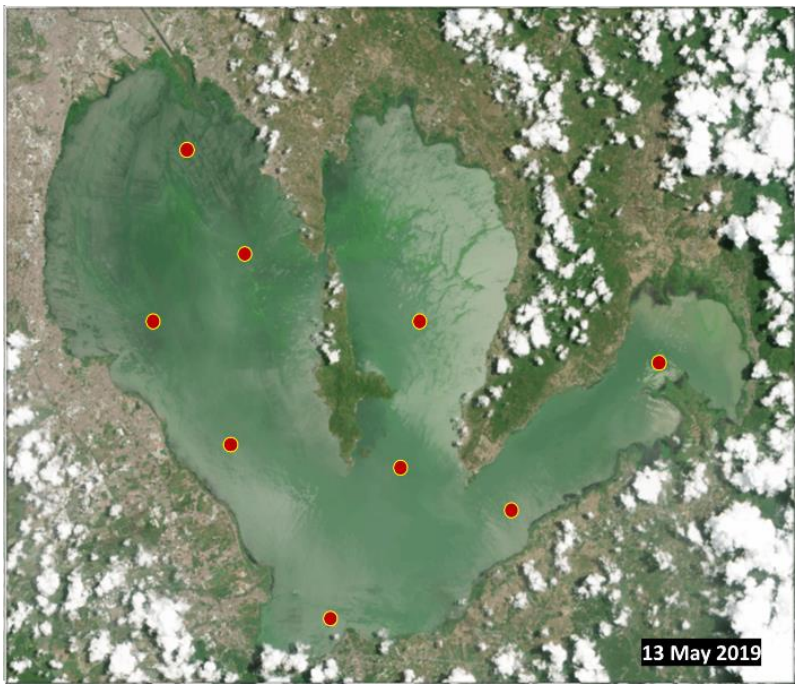

Figure 2. Landsat 8 image (acquired on 13 May 2019) showing the spatial variation of "greenness" considered as indication of varying levels of abundance of phytoplankton. The red circles indicate the water quality monitoring stations of the Laguna Lake Development Authority

As shown in Figure 1, Laguna Lake is connected to Manila Bay through the Pasig River, which serves as the only outlet of the lake. During dry season, backflow occurs making the water brackish with the intrusion of saline water (Santos-Borja and Nepomuceno, 2003). The lake is surrounded by Metro Manila and the Provinces of Laguna, Rizal, Cavite, Batangas, and Quezon. Its watershed has an area of about 2,980 sq. km. (Santos-Borja and Nepomuceno, 2003). Water quality degradation has been observed in Laguna Lake due to intensified exploitation of the its resources and pollution from industrial, household, and agricultural sources (Delos Reyes and Martens, 1994; Tamayo-Zafaralla et al., 2010).

\subsection{Field Surveys}

Field surveys were conducted in the lake on 13-17 November 2018 using FluoroProbe, a submersible fluorimeter capable of quantifying concentrations of spectral classes of microalgae. FluoroProbe, water quality, and spectral measurements were taken at forty-seven (47) stations in the lake (see Figure 3). In situ water quality measurements of turbidity, chl-a, conductivity, temperature, and $\mathrm{pH}$ were conducted using the AAQ multiparameter water quality instrument.

\subsection{Sentinel-3 OLCI Data}

OLCI provides the opportunity and capability to monitor aquatic environments utilizing nine (9) spectral bands, which allows to retrieve detailed information about the water quality of various type of waters (Blix et al., 2018). In this study, 10-day composite Sentinel-3 reflectance images were downloaded from the Copernicus Global Land Service (CGLS), which is a component of the Land Monitoring Core Service (LMCS) of the European flagship programme on Earth Observation called Copernicus. CGLS "systematically produces a series of qualified biogeophysical products on the status and evolution of the land surface, at global scale and at mid to low spatial resolution, complemented by the constitution of long-term time series" ( see https://land.copernicus.eu/global/). This study did not consider the Level 2 (L2) products which have been available for the public since July 2017.

\subsection{Correlation and Regression Analysis}

The chl-a (total and spectral class-differentiated) concentration values were tested for correlation and regressed with reflectance data obtained from 10-day composite Sentinel-3 reflectance images. downloaded from the Copernicus Global Land Service. In addition, ten (10) empirical algorithms (indices) for OLCI based on previous studies were also used in the regression analysis as listed below:

$\begin{array}{ll}\text { - } & R 560 / R 665 \\ \text { - } & R 665 / R 709 \\ \text { - } & R 65 / R 754 \\ \text { - } & R 674 / R 709 \\ \text { - } & \text { R709/R754 } \\ \text { - } & (1 / R 665-1 / R 709) \times R 754 \\ \text { - } & \text { R790 - R665)/R560 } \\ \text { - } & \text { R709-R754 }\end{array}$

In this study, the reflectance bands In multiple regression, variables with the highest variance inflation factor (VIF) are eliminated one at a time until all variables have VIF less than or equal to 7.5 .

\section{RESULTS AND DISCUSSION}




\subsection{Spatial Variation of Chl-a}

As shown in Figure 3, chl-a concentrations were high in the central lobe of Laguna Lake. In the west lobe, there are areas where the chl-a levels were also relatively high. What is noticeable from Figure 3 is the dominance of diatoms in most parts of the lake. However, bluegreens were relatively more abundant in the central lobe. Green microalgae were considerably dominant in some areas of the east lobe of the lake.

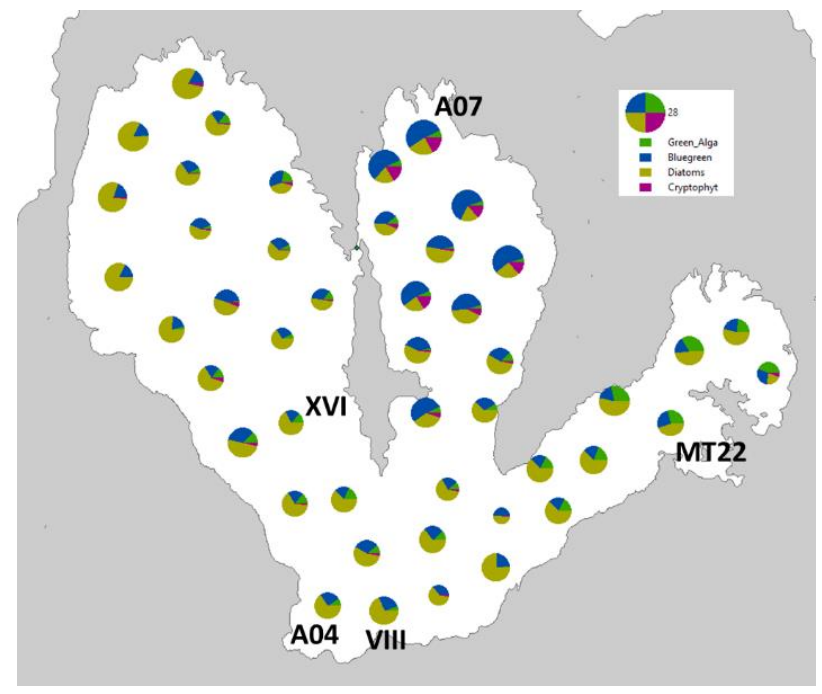

Figure 3. Spatial distribution of chl-a (ug/L) as measured using FluoroProbe. The size of the pie indicates the total chl-a relative to the legend and the colors of the pie sectors indicate the percentage of green microalgae, bluegreen microalgae (cyanobacteria), diatoms, and cryptophytes.

\subsection{Spectral Signatures}

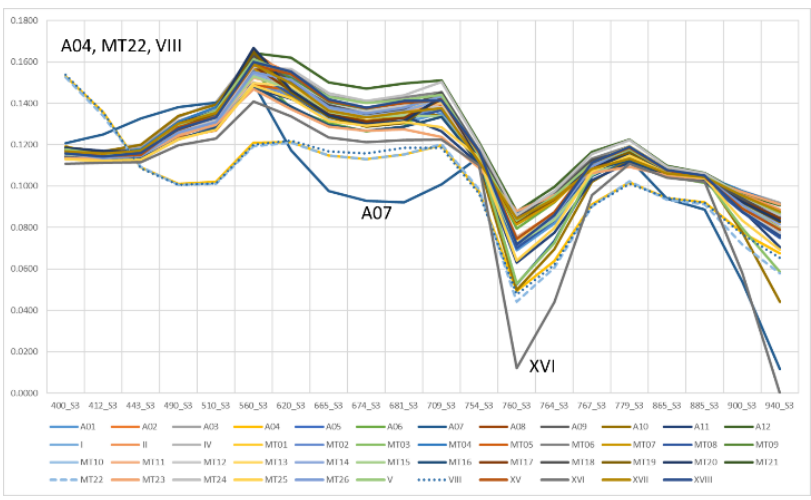

Figure 4. Spectral signatures obtained at the Laguna Lake water quality survey stations shown in Figure 3. Labelled lines are significantly different from the rest.

The spectral signatures obtained for each of the stations in Figure 3 were similar to each except at five (5) stations, namely, A04, MT22, VIII, A07, and XVI (Figure 4). These stations can be removed in the subsequent regression analysis as optical water quality types at these stations were considerably different Considering the majority of the spectral signatures, local peaks can be observed at R560, R709, and R779. Local dips are located at R665, R674, R681, and R760. These peaks and dips might be useful in developing indices for spectral class-differentiated chla estimation.

Further examination of the field spectral data at the survey stations using factor analysis yielded similar results. The first two factors F1 and F2 accounted for $83.47 \%$ of the data variability. As shown in Figure 5, points representation stations A07, XVI, MT22, A04, and VIII are separated clearly from the cloud of points representing all other stations.

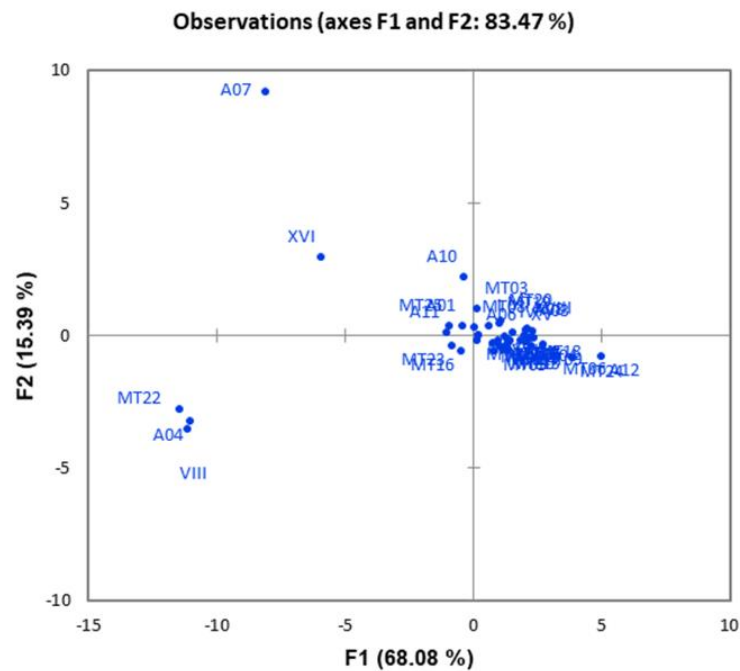

Figure 5. Scatter plot of the spectral data obtained for each station based on the results of factor analysis.

\subsection{Correlation Levels}

Weak correlations were observed between the microalgal concentrations and the band reflectance data (Figure 6). This points to the need to utilize in combination these bands. However, bands to be included in a model must be carefully chosen as multicollinearity will be a problem since most of the bands are highly intercorrelated positively.

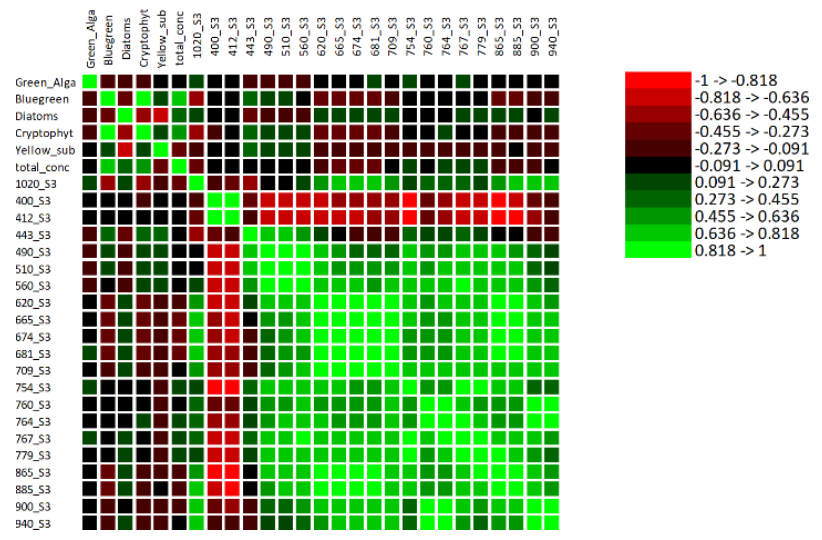

Figure 6. Correlation diagram for total and spectral classdifferentiated chl-a and Sentinel-3 band reflectance data.

The ten (10) Sentinel-3 OLCI indices were more strongly correlated with total chl-a concentration (Figure 7). This is 
especially true for R665/R709, R674/R709, and (1/R6651/R709)xR754 with the following respective correlation values: $-0.623,-0.646$, and 0.628 . The correlation of these indices with the class-differentiated microalgal concentration is shown in Table 1 . These are generally much lower compared to that of total chl-a, indicating the apportioning chl-a contributions to microlagal classes is difficult. It should be noted that per microalgal class, at least two of the indices turned out to be significant at alpha $=0.05$.

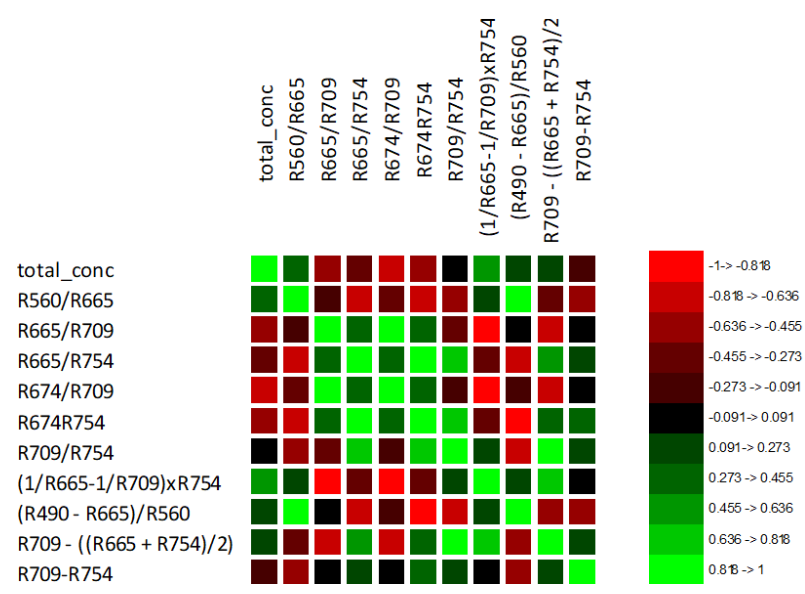

Figure 7. Correlation diagram for total chl-a and Sentinel-3 OLCI indices for chl-a estimation.

\begin{tabular}{|c|c|c|c|c|c|c|}
\hline Variables & Green_Alga & Bluegreen & Diatoms & Cryptophyt & w_sub & otal_conc \\
\hline Green_Alga & 1 & -0.213 & -0.167 & -0.178 & -0.087 & 0.044 \\
\hline Bluegreen & -0.213 & 1 & -0.406 & 0.909 & 0.227 & 0.620 \\
\hline Diatoms & -0.167 & -0.406 & 1 & -0.425 & -0.804 & 0.364 \\
\hline Cryptophyt & -0.178 & 0.909 & -0.425 & 1 & 0.189 & 0.567 \\
\hline Yellow_sub & -0.087 & 0.227 & -0.804 & 0.189 & 1 & -0.507 \\
\hline total_conc & 0.044 & 0.620 & 0.364 & 0.567 & -0.507 & 1 \\
\hline R560/R665 & -0.345 & 0.472 & -0.281 & 0.421 & 0.247 & 0.110 \\
\hline R665/R709 & 0.105 & -0.444 & -0.272 & -0.264 & 0.376 & -0.631 \\
\hline R665/R754 & -0.036 & -0.311 & -0.089 & -0.204 & 0.197 & -0.404 \\
\hline R674/R709 & 0.117 & -0.459 & -0.260 & -0.280 & 0.365 & -0.633 \\
\hline R674/R754 & -0.003 & -0.381 & -0.105 & -0.254 & 0.221 & -0.475 \\
\hline R709/R754 & -0.145 & 0.210 & 0.205 & 0.108 & -0.217 & 0.321 \\
\hline (1/R665-1/R709)xR754 & -0.113 & 0.444 & 0.268 & 0.262 & -0.366 & 0.623 \\
\hline (R490 - R665)/R560 & -0.367 & 0.390 & -0.365 & 0.394 & 0.349 & -0.047 \\
\hline$R 709-((R 665+R 754) / 2)$ & -0.118 & 0.353 & 0.261 & 0.203 & -0.328 & 0.525 \\
\hline R709-R754 & -0.132 & -0.112 & 0.227 & -0.255 & -0.089 & -0.016 \\
\hline
\end{tabular}

Table 1. Correlation of total and class-differentiated microalgal chl-a concentration with selected indices

\subsection{Total Chl-a Concentration}

Multiple regression results indicate that $48 \%$ of the variability of total chl-a concentration is explained by five explanatory (reflectance) variables (R412, R443, R560, R681, and R754) with RMSE of $2.814 \mathrm{ug} / \mathrm{l}$. In contrast, the two indices R674/R754 and (1/R665-1/R709)xR754 accounted for about $46 \%$ of the variability of total chl-a concentration with RMSE of $2.475 \mathrm{ug} / \mathrm{l}$. The equations for these two total chl-a models are given below.

Model 1:

Total chl-a $=20.086-213.721 * \mathrm{R} 560-314.078 * \mathrm{R} 681+$ $409.807 * \mathrm{R} 709+304.925 * \mathrm{R} 764-176.081 * \mathrm{R} 940$

Model 2:

Total chl-a $=29.968-14.302 * \mathrm{R} 674 / \mathrm{R} 754+62.278 *(1 / \mathrm{R} 665-$ 1/R709)xR754

\subsection{Spectral Class-differentiated Chl-a}

For diatoms and bluegreen microalgae, R560/R665 and (1/R6651/R709)xR754 constitute the models with $\mathrm{R}^{2}$ of 0.21 and 0.435 , and RMSE of 2.516 and $2.163 \mathrm{ug} / \mathrm{l}$, respectively. Green microalgal concentration is jointly described by three indices: R560/R665, R674/R754, and R709-R754. This yielded an $\mathrm{R}^{2}=0.182$ and $\mathrm{RMSE}=1.219 \mathrm{ug} / \mathrm{l}$. For cryptophytes, the model comprising of R560/R665, (1/R665-1/R709)xR754, and R709$\mathrm{R} 754$ produced an $\mathrm{R}^{2}=0.289$ and $\mathrm{RMSE}=0.767 \mathrm{ug} / \mathrm{l}$.

The relatively lower goodness of fit indicates that estimating spectral class-differentiated chl-a concentration from Sentinel-3 OLCI data is challenging but promising. The low $\mathrm{R}^{2}$ values can be attributed to the low resolution of OLCI data. The use of 10day composite data is also a limitation as the date of reflectance data acquisition may not directly match the date of the actual field surveys. Furthermore, more class-differentiated chl-a data should be collected to further improve the model.

\section{CONCLUSIONS}

Concentration of spectral microalgal classes can be estimated to a certain degree of accuracy using Sentinel-3 OLCI reflectance data and indices derived from them. Based on this study, bluegreens and cryptophytes are better estimated compared to diatoms and greens. The preliminary models showed that the following indices are useful of estimating abundance of spectral class-differentiated microalgae: R560/R66, (1/R665 - 1/R709) x R754, and R674/R754. This study is the first attempt to

\section{ACKNOWLEDGEMENTS}

This research was done as part of the Multi-platform and Crosssensor Water Quality Monitoring (MCWQM) Project. The Project was implemented by the University of the Philippines Training Center for Applied Geodesy and Photogrammetry (TCAGP), through the support of the Department of Science and Technology (DOST) of the Republic of the Philippines and the Philippine Council for Industry, Energy, and Emerging Technology Research and Development (PCIEERD). The Project was also implemented in collaboration with the Laguna Lake Development Authority (LLDA). Dissemination of this research is supported by the UP-DOST-SEI Engineering Research and Development for Technology (ERDT) Program.

\section{REFERENCES}

Blix, K., Pálffy, K., Tóth, V.R. and Eltoft, T. (2018). Remote Sensing of Water Quality Parameters over Lake Balaton by Using Sentinel-3 OLCI. Water 2018, 10, 1428; doi:10.3390/w10101428

Bresciani, M., Stroppiana, D., Odermatt, D., Morabito G., Giardino, C. (2011). Assessing remotely sensed chlorophyll-a for the implementation of the Water Framework Directive in European perialpine lakes. Science of The Total Environment 409(17):3038-91. doi.org/10.1016/j.scitotenv.2011.05.001.

Chen, X. and Feng, L. (2016). Remote Sensing of Lakes' Water Environment. Comprehensive Remote Sensing, pp.249-277. 
Delos Reyes, M. and Martens, R. (1994). Geoecology of Laguna de Bay, Philippines I. Techno-commercial impact on the trophic level structure of the Laguna de Bay aquatic ecosystem 19681980. Ecological Modelling, 75-76, pp.497-509.

Dörnhöfer, K. and Oppelt, N. (2016). Remote sensing for lake research and monitoring - Recent advances. Ecological Indicators, 64, pp.105-122.

Laguna Lake Development Authority. (2017). 2017 Annual Report.

Manzo, C., Bresciani, M., Giardino, C., Braga, F. and Bassani, C. (2015). Sensitivity analysis of a bio-optical model for Italian lakes focused on Landsat-8, Sentinel-2 and Sentinel-3. European Journal of Remote Sensing, 48(1), pp.17-32.

Palmer, S., Kutser, T. and Hunter, P. (2015). Remote sensing of inland waters: Challenges, progress and future directions. Remote Sensing of Environment, 157, pp.1-8.

Petus C., Waterhouse J., Lewis S., Vacher M., Tracey D., Devlin M. (2019) A flood of information: Using Sentinel-3 water colour products to assure continuity in the monitoring of water quality trends in the Great Barrier Reef (Australia). J Environ Manage. 2019 Oct 15;248:109255. doi: 10.1016/j.jenvman.2019.07.026. Epub 2019 Jul 26.

Tamayo-Zafaralla, M., Santos, R., Orozco, R. and Elegado, G. (2002). The ecological status of Lake Laguna de Bay, Philippines. Aquatic Ecosystem Health \& Management, 5(2), pp.127-138.

Toming, K, Kutser, T., Uiboupin, R., Arikas. A., Vahter, K., and Paavel, B. (2017) Mapping Water Quality Parameters with Sentinel-3 Ocean and Land Colour Instrument Imagery in the Baltic Sea. Remote Sensing, 9, 1070; doi:10.3390/rs9101070

Santos-Borja, A., Nepomuceno, D. S. (2003). Experience and Lessons Learned Brief for Laguna de Bay, Philippines. Lake Basin Management Initiative ILEC/LakeNet Regional Workshop for Asia: Sharing Experience and Lessons Learned in Lake Basin Management.

Schaeffer, B., Schaeffer, K., Keith, D., Lunetta, R., Conmy, R. and Gould, R. (2013). Barriers to adopting satellite remote sensing for water quality management. International Journal of Remote Sensing, 34(21), pp.7534-7544. 